\title{
Type II cGMP-dependent protein kinase directly inhibits HER2 activation of gastric cancer cells
}

\author{
MIAOLIN ZHU, XIAOYUAN YAO, MIN WU, HAI QIAN, YAN WU and YONGCHANG CHEN \\ Department of Physiology, School of Medicine, Jiangsu University, Zhenjiang, Jiangsu 212013, P.R. China
}

Received February 11, 2015; Accepted December 2, 2015

DOI: $10.3892 / \mathrm{mmr} .2015 .4688$

\begin{abstract}
Our previous study demonstrated that type II cyclic guanosine monophosphate (cGMP)-dependent protein kinase (PKG II) inhibited epidermal growth factor (EGF)-induced phosphorylation/activation of epidermal growth factor receptor (EGFR). Since human epidermal growth factor receptor 2 (HER2) has a similar molecular structure to EGFR, the present study was designed to investigate whether PKG II also inhibits HER2 activation. The human gastric cancer cell line HGC-27 was infected with an adenoviral construct encoding cDNA of PKG II (Ad-PKG II) to increase the expression of PKG II and treated with 8-(4-chlorophenylthio)guanosine-3',5'-cyclic monophosphate (8-pCPT-cGMP) to activate the kinase. Western blotting was performed to detect the tyrosine and serine/threonine phosphorylation of HER2. Co-immunoprecipitation was performed in order to determine the binding between PKG II and HER2. In addition, a QuikChange Lightning Site-Directed Mutagenesis kit was used to mutate threonine 686 of HER2 to glutamic acid or alanine. The results demonstrated that EGF treatment increased the tyrosine phosphorylation (activation) of HER2. Increasing the PKG II activity of HGC-27 cells through infection with Ad-PKG II and stimulation with 8-pCPT-cGMP inhibited the EGF-induced tyrosine phosphorylation/activation of HER2. PKG II bound directly with HER2 and caused phosphorylation of threonine 686 . When threonine 686 of HER2 was mutated to alanine, which could not be phosphorylated by PKG II, the inhibitory effect of PKG II on the activation of HER 2 was eradicated. When threonine 686 of HER2 was mutated to glutamic acid, which mimicked the phosphorylation of this site, treatment with EGF had no stimulating effect on tyrosine phosphorylation/activation of the mutant HER2.
\end{abstract}

Correspondence to: Professor Yongchang Chen, Department of Physiology, School of Medicine, Jiangsu University, 301 Xuefu Road, Zhenjiang, Jiangsu 212013, P.R. China

E-mail: ycchen54@ujs.edu.cn

Key words: type II cyclic guanosine monophosphate-dependent protein kinase, receptor tyrosine-protein kinase ErbB-2/human epidermal growth factor receptor 2, phosphorylation, gastric cancer
The results suggested that PKG II inhibits EGF-induced activation of HER2 through binding with and causing threonine 686 phosphorylation of this oncogenic protein.

\section{Introduction}

Receptor tyrosine-protein kinase ErbB-2 is a protein that is encoded by the ERBB2 gene in humans. The ERBB2 gene is also termed human epidermal growth factor receptor 2 (HER2). The ErbB-2/HER2 protein is a member of the epidermal growth factor receptor (EGFR/ErbB) family. Amplification or overexpression of HER2 has been demonstrated to be important in the development and progression of certain types of cancer, including gastric cancer (1-3).

Similar to other members of the ErbB family, HER2 contains an extracellular ligand binding domain, a transmembrane domain and an intracellular domain that can interact with a multitude of signaling molecules and exhibit ligand-dependent and ligand-independent activity (4). However, to date, no ligand of HER2 has been identified in mammalian cells. Instead of being activated by binding with the ligand, HER 2 is activated predominantly through heterodimerizing with any of the other three members of the ErbB family, with preference to EGFR (5). Dimerization results in the autophosphorylation of tyrosine residues within the cytoplasmic domain of HER2 and initiates a variety of signaling pathways, including mitogen-activated protein kinase, phosphoinositide 3-kinase/Akt, phospholipase $\mathrm{C}$ /protein kinase $\mathrm{C}(\mathrm{PKC})$ and signal transducer and activator of transcription-mediated pathways (6).

Our previous study demonstrated that type II cyclic guanosine monophosphate (cGMP)-dependent protein kinase (PKG II) inhibited the activation of EGFR through binding with and causing phosphorylation of the receptor $(7,8)$. Since HER2 has a similar structure to EGFR and forms a dimer with EGFR, whether PKG II has an inhibitory effect on HER2 warrants further investigation. Therefore, the present study was designed to investigate the possible inhibition of HER 2 by PKG II.

\section{Materials and methods}

Cell line and reagents. The human gastric cancer cell line HGC-27 was provided by the Institute of Cell Biology (Shanghai, China). Adenoviral vectors encoding the cDNA $\beta$-galactosidase (Ad-LacZ) and PKG II (Ad-PKG II) were provided by Dr Gerry Boss and Dr Renate Pilz (University of California, San Diego, 
CA, USA). Dulbecco's modified Eagle's medium (DMEM) and fetal bovine serum (FBS) were obtained from Gibco (Thermo Fisher Scientific Inc., Waltham, MA, USA). The polyclonal rabbit anti-human PKG II antibody was obtained from Abgent Biotechnology (San Diego, CA, USA; cat. no. AP8001a; dilution, 1:200). The horseradish peroxidase (HRP)-conjugated monoclonal mouse anti-human $\beta$-actin antibody was obtained from Santa Cruz Biotechnology, Inc. (Santa Cruz, CA, USA; cat. no. sc-47778; dilution, 1:1,000). Polyclonal rabbit anti-p-ErbB2 (T686; cat. no. ab11717; dilution, 1:1,000) and polyclonal rabbit anti-human phosphoserine/threonine (cat. no. ab17464; dilution, 1:1,000) were purchased from Abcam (Cambridge, MA, USA). Polyclonal rabbit anti-human p-HER2 (Tyr1248) antibody (cat. no. BS4090; dilution, 1:500) and polyclonal rabbit anti-human ErbB2/HER2 (cat. no. BS1169; dilution, 1:500) were obtained from Bioworld Technology, Inc. (St. Louis Park, MN, USA). Monoclonal mouse anti-flag antibody (cat. no. F1804; dilution, 1:1,000) was purchased from Sigma-Aldrich (St. Louis, MO, USA). The HRP-conjugated polyclonal anti-mouse and anti-goat IgG secondary antibodies (cat. nos. 115-035-003 and 111-035-003, respectively; dilution, 1:10,000) were purchased from Jackson ImmunoResearch Laboratories (West Grove, PA, USA). The Bioepitope ${ }^{\circledR}$ protein $\mathrm{A}+\mathrm{G}$ Agarose IP was obtained from Bioworld Technology, Inc. The cellular permeable cGMP analog 8-(4-chlorophenylthio)guanosine-3',5'-cyclic monophosphate (8-pCPT-cGMP) was acquired from Calbiochem (San Diego, CA, USA). EGF was purchased from Sigma-Aldrich. The cell transfection reagent Lipofectamine ${ }^{\mathrm{TM}} 2000$ and E. coli BL-21DE3 were obtained from Invitrogen (Thermo Fisher Scientific, Inc.). The QuikChange Lightning Site-Directed Mutagenesis kit was purchased from Agilent Technologies (Santa Clara, CA, USA) and the SanPrep Column Plasmid Mini-Preps kit was obtained from Sangon Biotech Shanghai Co. Ltd. (Shanghai, China). Electrochemiluminescence (ECL) reagents were acquired from EMD Millipore (Billerica, MA, USA).

Cell culture and preparation of cell extracts. HGC-27 cells were cultured in DMEM supplemented with 10\% FBS and maintained at $37^{\circ} \mathrm{C}$ in a humidified incubator with $95 \%$ air and $5 \% \mathrm{CO}_{2}$. On the day prior to infection, cells were planted into 6 -well plates. To observe the phosphorylation of HER2, the cells were infected with Ad-LacZ or Ad-PKG II for $24 \mathrm{~h}$ and serum starved overnight. Subsequently, in the Ad-LacZ + EGF and Ad-PKG II + EGF groups, the cells were incubated with EGF $(100 \mathrm{ng} / \mathrm{ml})$ for $5 \mathrm{~min}$; in the Ad-PKG II + cGMP + EGF groups, the cells were incubated with 8-pCPT-cGMP for $1 \mathrm{~h}$ and then with EGF (100 ng/ml) for $5 \mathrm{~min}$. To observe PKGII binding with HER 2 directly and causing the serine/threonine phosphorylation of HER2, the cells were infected with Ad-PKG II for $24 \mathrm{~h}$, serum starved overnight and incubated with 8-pCPT-cGMP for $1 \mathrm{~h}$. At the end of the treatments, the cells were harvested by aspiration of the media and direct addition of heated $2 \mathrm{X}$ SDS sample buffer. The cell lysate was scraped and transferred to tubes, heated for $5 \mathrm{~min}$ at $100^{\circ} \mathrm{C}$ and stored at $-20^{\circ} \mathrm{C}$.

Co-immunoprecipitation $(C o-I P)$. The cells growing on the $100-\mathrm{mm}$ culture plate were washed two times with cold PBS and lysed by adding $1 \mathrm{ml}$ radioimmunoprecipitation assay buffer (Beyotime Institute of Biotechnology, Haimen, China; $50 \mathrm{mM}$ Tris- $\mathrm{HCl} \mathrm{pH} 7.4,1 \%$ Triton X-100, $1 \mathrm{mM}$ EDTA, $1 \mathrm{mM}$ leupeptin, $1 \mathrm{mM}$ phenylmethylsulfonyl fluoride, $10 \mathrm{mM}$ $\mathrm{NaF}, 1 \mathrm{mM} \mathrm{Na} \mathrm{VO}_{4}$ ) per plate. An antibody against tag protein flag was used for immunoprecipitation. The precipitates were probed with antibodies against target proteins.

Western blotting. Proteins were separated by SDS-PAGE (10\%) gel (EMD Millipore) according to the molecular size and transferred onto a polyvinylidene difluoride membrane (EMD Millipore). Blots were blocked with $5 \%$ (w/v) non-fat milk in Tris-buffered saline with Tween 20 for $1 \mathrm{~h}$ at room temperature and then incubated at $4^{\circ} \mathrm{C}$ overnight with the primary antibodies (including anti-p-HER 2 , anti- $\beta$-actin, anti-p-ErbB2/HER2, anti-phosphoserine/threonine and anti-flag), followed by incubation with the secondary antibodies (including goat anti-mouse and goat anti-rabbit HRP-conjugated antibodies) at room temperature for $1 \mathrm{~h}$. The signal was visualized using ECL detection reagents. To perform densitometry analysis, digital images of the positive bands were obtained with Chemidoc XRS and analyzed using the image analysis program Quantity One, version 4.6.2 (Bio-Rad Laboratories, Inc., Hercules, CA, USA). The results are presented as the ratio of target protein/loading control.

Construction of mutant plasmid. The cDNA encoding human HER 2 was cut off by HindIII from the plasmid CMV-HER2-WT (cat. no. 16257; Addgene, Cambridge, MA, USA) and was cloned into the expression vector p3XFlag-myc-CMV-24. Mutants of HER2 were generated using the QuikChange Site-Directed Mutagenesis kit (Stratagene, San Diego, CA, USA). Threonine 686 was mutated to glutamic acid (T686E) and alanine (T686A). The following primers were used: Mutant HER2 (T686E), forward 5'-GAAGATCCGGAAGTACGA GATGCGGAGACTGCTG-3' and reverse 5'-CAGCAGTCT CCGCATCTCGTACTTCCGGATCTTC-3'; mutant HER2 (T686A), forward 5'-GAAGATCCGGAAGTACGCGATGCG GA-GACTGCTG-3' and reverse CAGCAGTCTCCGCAT CTCGTACTTCCGGATCTTC. The mutant plasmids were sequenced and the mutations were confirmed.

Statistical analysis. The data are expressed as the mean \pm standard deviation. Statistical significance was performed using a two-tailed analysis of variance with SPSS statistical software, version 19 (IBM SPSS, Armonk, NY, USA). P<0.05 was considered to indicate a statistically significant difference.

\section{Results}

PKG II inhibits EGF-induced activation of HER2. The activation of HER2 is dependent on the ligand-receptor binding of other ErbB receptors, particularly EGFR. When EGF binds with EGFR, EGFR forms a dimer with HER2 and this dimerization causes autophosphorylation/activation of HER2 (5). Tyrosine 1248 (Tyr1248) is one of the autophosphorylation sites of HER2 and phosphorylation of this site is associated with downstream signaling (9). The present study investigated the inhibitory effect of PKG II on Tyr1248 phosphorylation of HER 2 in differently treated HGC-27 cells using western blotting. The results demonstrated that in Ad-LacZ-infected cells, 


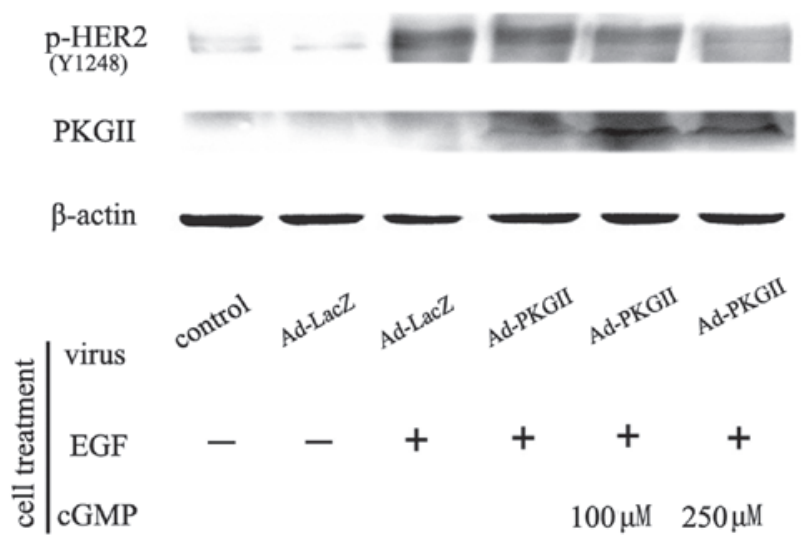

Figure 1. PKG II inhibits EGF-induced tyrosine 1248 phosphorylation of HER2. HGC-27 cells were infected with Ad-LacZ or Ad-PKG II for $24 \mathrm{~h}$ and serum starved overnight. Subsequently, in the Ad-LacZ+EGF and Ad-PKG II+EGF groups, cells were incubated with EGF $(100 \mathrm{ng} / \mathrm{ml})$ for 5 min. In the Ad-PKG II+cGMP+EGF groups, cells were incubated with 8-pCPT-cGMP for $1 \mathrm{~h}$ and then with EGF $(100 \mathrm{ng} / \mathrm{ml})$ for $5 \mathrm{~min}$. Cells were harvested and lysed as described in Materials and methods and the cell lysate was subjected to western blotting to detect the Tyr1248 phosphorylation of HER2. The results demonstrated that infection with Ad-PKG II increased the expression of PKG II. EGF treatment induced a marked increase in Tyr1248 phosphorylation of HER2. In addition, infection with Ad-PKG II+cGMP treatment inhibited the EGF-induced phosphorylation of HER2. The results are representative of three independent experiments. EGF, epidermal growth factor; PKG II, type II cGMP-dependent protein kinase; HER2, human epidermal growth factor receptor 2; Ad, adenovirus; LacZ, $\beta$-galactosidase; 8-pCPT-cGMP, 8-(4-chlorophenylthio)guanosine-3',5'-cyclic monophosphate.

there was a pronounced increase in Tyr1248 phosphorylation of HER2 when the cells were incubated with EGF $(100 \mathrm{ng} / \mathrm{ml})$ for $5 \mathrm{~min}$. In cells infected with Ad-PKG II for $24 \mathrm{~h}$, treated with 8-pCPT-cGMP for $1 \mathrm{~h}$ and then incubated with EGF (100 $\mathrm{ng} / \mathrm{ml}$ ) for $5 \mathrm{~min}$, the Tyr1248 phosphorylation of HER2 was significantly decreased (Fig. 1). This indicated that PKG II could inhibit EGF-induced Tyr1248 phosphorylation of HER2.

PKG II directly binds with and causes phosphorylation of HER2. Since the phosphorylation/activation of HER2 was caused by EGF/EGFR binding and PKG II has been reported to bind with EGFR (10), whether PKG II directly inhibits HER2 or the inhibition is subsequent to its inhibition of EGFR requires further investigation. Co-IP was performed to detect the possible interaction between PKG II and HER2. The results demonstrated that in HGC-27 cells infected with Ad-PKG II and stimulated with 8-pCPT-cGMP, binding between PKG II and HER2 occurred (Fig. 2). Western blotting with antibodies against pan serine/threonine phosphorylation was used to detect the PKG II-induced serine/threonine phosphorylation of HER2. The results demonstrated that in cells infected with Ad-PKG II and treated with 8-pCPT-cGMP, there was a pronounced increase in serine/threonine phosphorylation of HER2 (Fig. 3). These results indicated that PKG II inhibited the tyrosine phosphorylation/activation of HER2 through directly binding with HER 2 and causing phosphorylation.

Threonine 686 is a PKG II-specific phosphorylation site of $H E R 2$. In order to reveal the PKG II-specific phosphorylation
A

Input IgG

IP

(HER2)

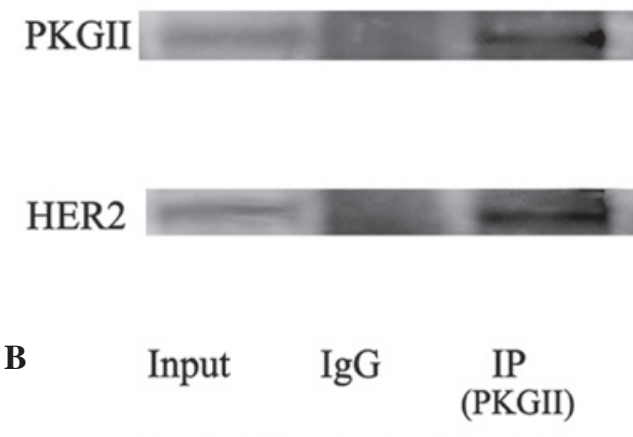

HER2

(PKGII)
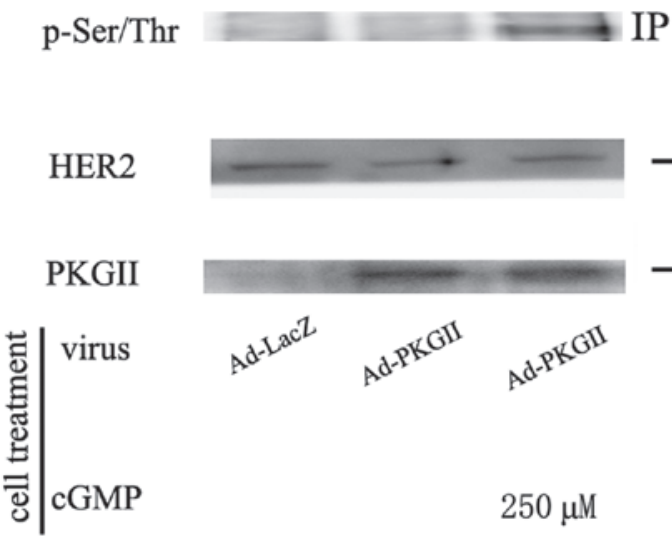

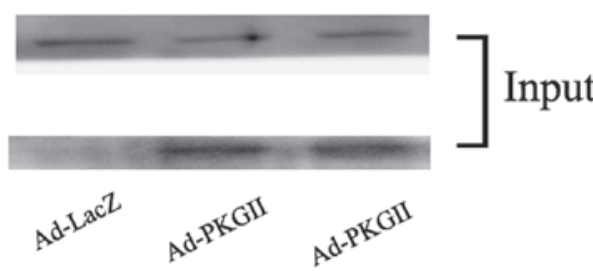

$250 \mu \mathrm{M}$

Figure 3. PKG II causes pan-serine/threonine phosphorylation of HER2. HGC-27 cells were treated the same as in Fig. 2. Immunoprecipitation with an antibody against HER 2 was performed to isolate and concentrate the protein. Western blotting with anti pan-serine/threonine phosphorylation antibody was performed to detect the PKG II-induced phosphorylation of precipitated HER2. The results demonstrated that PKG II caused serine/threonine phosphorylation of HER2. The results are representative of three independent experiments. PKG II, type II cGMP-dependent protein kinase; HER2, human epidermal growth factor receptor 2; Ad-LacZ, $\beta$-galactosidase; Ad, adenovirus; cGMP, cyclic guanosine monophosphate; IP, immunoprecipitation.

site of HER2, western blotting with antibodies against p-HER2 (T686) was used to detect the phosphorylation of threonine 686 on HER2 in cells infected with Ad-PKG II and treated with 8-pCPT-cGMP. The results demonstrated that 

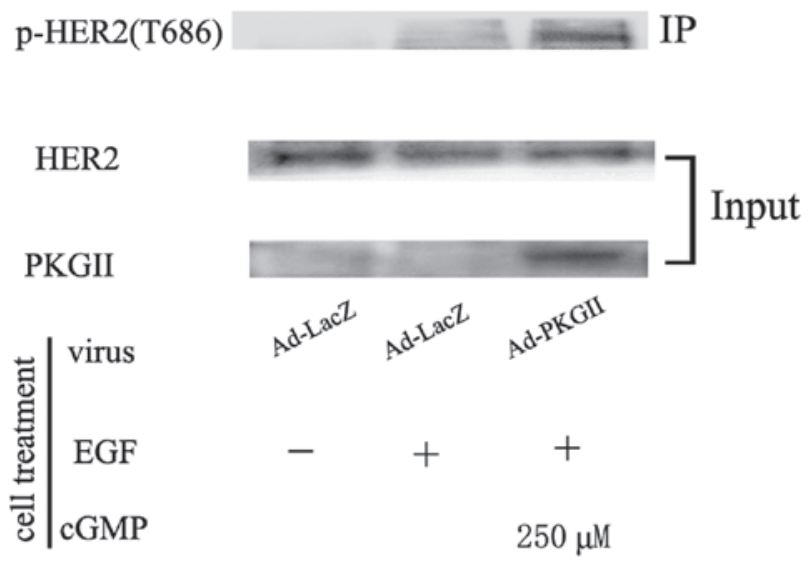

Figure 4. Threonine 686 of HER2 is a PKG II-specific phosphorylation site. HGC-27 cells were treated the same as in Fig. 2. HER2 protein was isolated and concentrated by immunoprecipitation with an antibody against HER 2 and western blotting with anti p-HER2 (T686) antibody was performed to detect the threonine 686 phosphorylation of HER2 caused by PKG II. The results demonstrated that PKG II caused threonine 686 phosphorylation of HER2. The results are representative of three independent experiments. PKG II, type II cGMP-dependent protein kinase; HER2, human epidermal growth factor receptor 2; EGF, epidermal growth factor; Ad-LacZ, $\beta$-galactosidase; Ad, adenovirus; IP, immunoprecipitation.

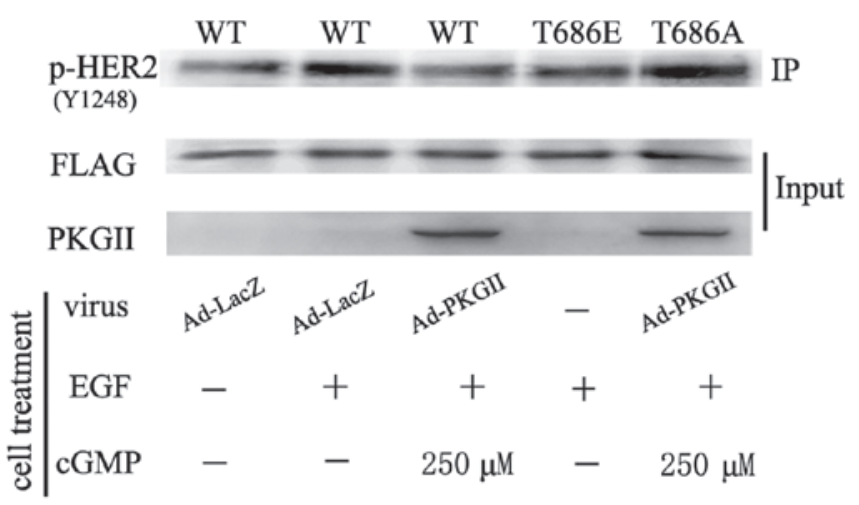

Figure 5. Threonine 686 phosphorylation is associated with HER2 activation. HGC-27 cells were transfected with plasmids encoding cDNA of WT HER2, threonine 686-glutamic acid mutant HER2 (T686E) and threonine 686A-alanine mutant HER2 (T686A). On day 2 after transfection, the cells were infected with Ad-LacZ or Ad-PKG II overnight and serum starved for $12 \mathrm{~h}$. Subsequently, the cells were treated with 8-pCPT-cGMP for $1 \mathrm{~h}$ and subsequently incubated with EGF for $10 \mathrm{~min}$. The lysate of the cells was subjected to western blotting to detect the tyrosine phosphorylation/activation of HER2. The results demonstrated that in cells transfected with plasmid of T686E, EGF-treatment did not cause tyrosine phosphorylation of HER2, indicating that the mimic of threonine 686 phosphorylation of HER 2 could inhibit the activation of HER2. In cells transfected with the T686A plasmid, PKG II could not inhibit HER2 activation and did not phosphorylate HER2 on T686, indicating that PKG II-induced threonine 686 phosphorylation of HER2 was crucial for inhibition of HER2. The results are representative of three independent experiments. HER2, human epidermal growth factor receptor 2; EGF, epidermal growth factor; WT, wild type; PKG II, type II cGMP-dependent protein kinase; Ad, adenovirus; Ad-LacZ, $\beta$-galactosidase; Ad, adenovirus; IP, immunoprecipitation.

PKG II caused a pronounced increase in phosphorylation of threonine 686 (Fig. 4). To further determine if this site was the main site for PKG II-induced phosphorylation, plasmids encoding the cDNA of flag-tagged wild-type and mutant HER2 were constructed. The cells were transfected with the plasmids to express the mutants of HER 2 and the proteins were isolated by immunoprecipitating with antibody against flag. Western blotting with antibody against pan serine/threonine phosphorylation was applied to detect the phosphorylation of the precipitated HER2 proteins. The results demonstrated that PKG II did not cause serine/threonine phosphorylation of the T686A mutant of HER2 and had no inhibitory effect on HER2 tyrosine phosphorylation/activation, confirming that threonine 686 was the main phosphorylating site of PKG II. Furthermore, EGF had no stimulating effect on the T686E mutant of HER2, indicating that the mimic of threonine 686 phosphorylation prevented the activation of HER2 by EGF (Fig. 5). These results confirmed that threonine 686 was the PKG II-specific phosphorylation site of HER2 and the phosphorylation of this site was crucial for the inhibition of HER2 activation by PKG II.

\section{Discussion}

Gastric cancer is the fourth most commonly diagnosed cancer and the second most common cause of cancer-associated mortality worldwide (11). Extensive research is being performed to improve the diagnosis and treatment of the disease. Amplification of the HER2 gene and overexpression of the HER2 protein in gastric cancer have been confirmed by a large number of studies, indicating that HER2 is important in the occurrence and development of this tumor $(2,3)$. HER2 forms homo- and heterodimers and serves as a critical dimerization partner for other members of the HER/ErbB family, and leads to activation of downstream signaling pathways associated with cell proliferation, differentiation, survival and angiogenesis (12). Among the other members of the HER family, EGFR (HER1) is the most extensively investigated. When EGF binds with EGFR, the binding causes dimerization of EGFR with other members of the HER family, with HER2 as the preferential partner (13). The dimerization then causes auto-tyrosine phosphorylation of the receptors. The phosphorylated tyrosine sites can recruit downstream signaling molecules and initiate several signaling pathways (14). Thus, inhibiting HER2 activity is important for interfering with the growth and development of gastric cancer.

Our previous study demonstrated that PKG II inhibited the activation of EGFR directly, potentially through binding with EGFR and causing serine/threonine phosphorylation of EGFR (10). Since HER2 has a similar structure to EGFR, the present study aimed to investigate whether PKG II directly inhibits HER 2. The Co-IP results demonstrated that PKG II could bind with HER2. However, since HER2 could dimerize with EGFR and PKG II could bind with EGFR, whether the binding between PKG II and HER2 was a direct or an indirect one required further investigation. In order to answer this question, the phosphorylation of HER2 by PKG II was examined. The results demonstrated that PKG II caused phosphorylation of HER2 and the phosphorylation site was threonine 686. This confirmed that PKG II bound directly with HER2 and phosphorylated it.

Similar to EGFR, HER2 exhibits two kinds of phosphorylation during its participating signal transduction. One is tyrosine phosphorylation caused by ligand binding and dimerizing. The phosphorylated tyrosine residue may act as a docking site for downstream signaling molecules (14). 
Another one is serine/threonine phosphorylation caused by serine/threonine protein kinases, including protein kinase A (PKA) and PKC. The phosphorylation of serine/threonine on HER2 is important in regulating its activity. Threonine 686 is located within the juxtamembrane domain of HER 2 and phosphorylation of this site by different protein kinases has different functions. For example, Gulliford et al reported that PKC caused T686 phosphorylation of HER2 and stimulated the internalization and signaling of the ligand-activated receptor (15). Monje et al reported that PKA phosphorylated T686 on HER2 and produced synergistic enhancement of neuregulin-induced HER2-HER3 activation and proliferation of Schwann cells (16). In the present study, the results indicated that PKG II-induced T686 phosphorylation of HER2 was associated with inhibition of this receptor. The causes of these differences require further investigation in the future.

Our previous results demonstrated that PKG II had an inhibitory effect on EGFR activation and the results in the present study demonstrated that PKG II had an inhibitory effect on HER2 activation. These results suggested that PKG II could inhibit EGFR and HER2 simultaneously. This inhibitory pattern is significant as dual inhibition is more effective in cancer therapy. For example, Fink et al reported that a compound with dual inhibitory effects on EGFR and HER2 demonstrated promising efficacy in EGFR and HER2-driven human tumor xenograft models $(17,18)$. Thus, this suggests that PKG II is a potential efficient cancer inhibitor. This provides new options for cancer therapy.

\section{Acknowledgements}

This study was supported by the National Natural Science Foundation of China (grant nos. 81272755, 81201959 and 81001100), the Specialized Research Fund for Senior Personnel Program of Jiangsu University (grant no. 11JDG114), the Natural Science Foundation of Colleges and Universities of Jiangsu Province (grant no. 12KJB310001, the Postdoctoral Research Funding Plan of Jiangsu Province (grant no. 1401144C) and the China Postdoctoral Science Foundation (grant no. 2014M561599). The authors would like to thank Dr Gerry Boss and Dr Renate Pilz from the University of California for providing the adenoviral constructs.

\section{References}

1. Ménard S, Casalini P, Campiglio M, Pupa SM and Tagliabue E: Role of HER $2 /$ neu in tumor progression and therapy. Cell Mol Life Sci 61: 2965-2978, 2004.
2. Kim KC, Koh YW, Chang HM, Kim TH, Yook JH, Kim BS, Jang SJ and Park YS: Evaluation of HER2 protein expression in gastric carcinomas: Comparative analysis of 1,414 cases of whole-tissue sections and 595 cases of tissue microarrays. Ann Surg Oncol 18: 2833-2840, 2011.

3. Jørgensen JT: Role of human epidermal growth factor receptor 2 in gastric cancer: Biological and pharmacological aspects. World J Gastroenterol 20: 4526-4535, 2014.

4. Olayioye MA: Update on HER-2 as a target for cancer therapy: Intracellular signaling pathways of ErbB2/HER-2 and family members. Breast Cancer Res 3: 385-389, 2001

5. Olayioye MA, Graus-Porta D, Beerli RR, Rohrer J, Gay B and Hynes NE: ErbB-1 and ErbB-2 acquire distinct signaling properties dependent upon their dimerization partner. Mol Cell Biol 18: 5042-5051, 1998

6. Roy V and Perez EA: Beyond trastuzumab: Small molecule tyrosine kinase inhibitors in HER-2-positive breast cancer. Oncologist 14: 1061-1069, 2009.

7. Wu Y, Chen Y, Qu R, Lan T and Sang J: Type II cGMP-dependent protein kinase inhibits EGF-triggered signal transduction of the MAPK/ERK-mediated pathway in gastric cancer cells. Oncol Rep 27: 553-558, 2012.

8. Lan T, Chen Y, Sang J, Wu Y, Wang Y, Jiang L and Tao Y: Type II cGMP-dependent protein kinase inhibits EGF-induced MAPK/JNK signal transduction in breast cancer cells. Oncol Rep 27: 2039-2044, 2012.

9. TaniyamaK,IshidaK,TodaT,MotoshitaJ,KuraokaK,Saito A,Tani Y, Uike T, Teramoto S and Koseki M: Tyrosine1248-phosphorylated HER2 expression and HER2 gene amplification in female invasive ductal carcinomas. Breast Cancer 15: 231-240, 2008.

10. Jiang L, Lan T, Chen Y, Sang J, Li Y, Wu M, Tao Y, Wang Y, Qian H and Gu L: PKG II inhibits EGF/EGFR-induced migration of gastric cancer cells. PLoS One 8: e61674, 2013.

11. Ferro A, Peleteiro B, Malvezzi M, Bosetti C, Bertuccio P, Levi F, Negri E, La Vecchia $C$ and Lunet N: Worldwide trends in gastric cancer mortality (1980-2011), with predictions to 2015 and incidence by subtype. Eur J Cancer 50: 1330-1344, 2014.

12. Hynes NE and MacDonald G: ErbB receptors and signaling pathways in cancer. Curr Opin Cell Biol 21: 177-184, 2009.

13. Olayioye MA, Neve RM, Lane HA and Hynes NE: The ErbB signaling network: Receptor heterodimerization in development and cancer. Embo J 19: 3159-3167, 2000.

14. Birtwistle MR, Hatakeyama M, Yumoto N, Ogunnaike BA, Hoek JB and Kholodenko BN: Ligand-dependent responses of the ErbB signaling network: Experimental and modeling analyses. Mol Syst Biol 3: 144, 2007.

15. Gulliford T, Ouyang $X$ and Epstein RJ: Intensification of growth factor receptor signalling by phorbol treatment of ligand-primed cells implies a dimer-stabilizing effect of protein kinase C-dependent juxtamembrane domain phosphorylation. Cell Signal 11: 245-252, 1999.

16. Monje PV, Athauda G and Wood PM: Protein kinase A-mediated gating of neuregulin-dependent ErbB2-ErbB3 activation underlies the synergistic action of cAMP on Schwann cell proliferation. J Biol Chem 283: 34087-34100, 2008.

17. Fink BE, Norris D, Mastalerz H, Chen P, Goyal B, Zhao Y, Kim SH, Vite GD, Lee FY, Zhang H, et al: Novel pyrrolo[2,1-f] $[1,2,4]$ triazin-4-amines: Dual inhibitors of EGFR and HER2 protein tyrosine kinases. Bioorg Med Chem Lett 21: 781-785, 2011.

18. Xia W, Mullin RJ, Keith BR, Liu LH, Ma H, Rusnak DW, Owens G, Alligood KJ and Spector NL: Anti-tumor activity of GW572016: A dual tyrosine kinase inhibitor blocks EGF activation of EGFR/erbB2 and downstream Erk1/2 and AKT pathways. Oncogene 21: 6255-6263, 2002. 